\title{
CONSUMO DE ENERGIA E EFICIÊNCIA DAS ESTAÇÕES DE BOMBEAMENTO DE LAVOURAS DE ARROZ IRRIGADO ${ }^{1}$
}

\author{
ENERGY CONSUMPTION AND EFFICIENCY Of WATER PUMPING \\ STATIONS TO IRRIGATE RICE CROP FIELDS
}

\author{
Elio Marcolin ${ }^{2}$ Adroaldo Dias Robaina ${ }^{3}$
}

RESUMO

Este trabalho teve como objetivo avaliar o consumo de energia e a eficiência das estações de bombeamento de lavouras de arroz irrigado, na localidade de Arroio Grande, município de Santa Maria, RS. Das 95 estações de bombeamento visitadas, 21 foram avaliadas quanto ao rendimento e consumo de energia. Os resultados evidenciaram que $67 \%$ das bombas operavam com rendimentos abaixo de $75 \%$. Houve uma grande amplitude na relação $\mathrm{CV} h \mathrm{a}^{-1}$ entre as fontes de potência, variando de $0,93 \mathrm{CV}$ ha ${ }^{1}$ (conjuntos motobombas elétricos) a 6,30CV ha $a^{-1}$ (acionados por tratores a diesel). Constatou-se que as potências nominais instaladas estavam de $200 \%$ a $4250 \%$ acima das necessárias e que há desperdício de energia na irrigação de lavouras de arroz. Verificou-se, também que, adequando-se as estações de bombeamento, é possível economizar $29 \%$ da energia elétrica com a redução das perdas de carga e $41 \%$, com a redução das perdas de carga e a substituição das atuais motobombas por outras com rendimentos mínimos de $75 \%$.

Palavras-chave:

rendimento das bombas, estações de bombeamento, bombas.

\section{SUMMARY}

The objective of this work was to evaluate the energy consumption and the efficiency of the water pumping stations to irrigate rice crop fields at Arroio Grande, Santa Maria county, RS, Brazil,. 95 water pumping stations were visited, but only 21 were avaluated considering yield. Results showed that $67 \%$ of the water pumping stations were under $75 \%$ of it is operational efficiency. The ratio $\mathrm{CV} \mathrm{ha-1}$ showed great amplitude between the different power sources. For electrical power stations the ratio was $0.93 \mathrm{CV} \mathrm{ha-1}$ and for water pumping systems moved by tractors the ratio was $6,30 \mathrm{CV} \mathrm{ha-1}$. It was noticed that all power stations operated between $200 \%$ and $4250 \%$ over what would be

\begin{abstract}
normally necessary to irrigate the rice cultivated area. It was also observed that, under safe conditions electric energy could be saved up to $29 \%$ by re-evaluating head losses and, $41 \%$ if included a substitution of the current equipments pumping systems, for others minimum efficiency of $75 \%$.
\end{abstract}

Key words: pumps efficiency, pumping stations, pumps.

\section{INTRODUÇÃO}

A área cultivada com arroz no Brasil, situa-se em torno de 3.616,2 mil hectares. O Rio Grande do Sul é o maior produtor com $26 \%$ dessa área, praticamente toda irrigada e representa $45 \%$ da produção nacional (CONAB, 2000).

A inundação é o sistema de irrigação mais antigo e simples utilizado na cultura de arroz irrigado (OLITA, 1985). No Rio Grande do Sul, as lavouras de arroz vêm sendo irrigadas nesse sistema desde 1903, sendo cultivados na safra 1999/2000, aproximadamente 950.000 ha (IRGA, 2000). O volume de água consumido na irrigação depende da textura e gradiente de declividade do solo, temperatura e umidade relativa do ar, determinando vazões contínuas de 1,5 a $2,0 \ell \mathrm{s}^{-1} \mathrm{ha}^{-1}$ num período médio de irrigação de 80 a 100 dias (EMBRAPA, 1999).

Atualmente, na irrigação do arroz, tem-se utilizado vazões de 1,7 a $3,0 \ell \quad \mathrm{s}^{-1} \quad \mathrm{ha}^{-1}$ (BERNARDES, 1946), as quais são

\footnotetext{
${ }^{1}$ Parte da Dissertação de Mestrado em Engenharia Agrícola da Universidade Federal de Santa Maria (UFSM).

${ }^{22}$ Engenheiro Agrônomo, MSc., Pesquisador do Instituto Rio Grandense do Arroz (IRGA), Av. Bonifácio Carvalho Bernardes, 1494, 94930-030, Cachoeirinha, RS. E-mail: elio_irga@redemeta.com.br. Autor para correspondência.

${ }^{3}$ Engenheiro Agrônomo, Doutor, Professor Titular do Departamento de Engenharia Rural, UFSM.
} 
demasiadamente elevadas, provocando assim, baixa eficiência do sistema adotado e do uso do recurso hídrico pelo complexo solo-planta (BELTRAME \& GONDIM 1982)

No entanto, segundo BELTRAME \& GONDIM (1982), a vazão de $1,44 \ell \mathrm{s}^{-1} \mathrm{ha}^{-1}$ seria suficiente para suprir a necessidade de irrigação da lavoura de arroz, reduzindo em 18\% o volume de água e, consequentemente, o consumo de energia.

A evapotranspiração da cultura de arroz irrigado no Rio Grande do Sul com período de irrigação de 90 dias, consome, em média, 610,4 a 771,6mm (MOTTA et al., 1990). Segundo os autores, esses totais representam, aproximadamente, $70 \%$ da água consumida no sistema de irrigação por inundação contínua. Portanto, o volume total corresponde a vazões de 1,12 a $1,42 \ell \mathrm{s}^{-1} \mathrm{ha}^{-1} \mathrm{de}$ acordo com a localidade e tipo de solo utilizado.

Segundo MARCOLIN et al. (1999), o consumo de água diferencia-se entre os sistemas de cultivo de arroz utilizados no Rio Grande do Sul. Em experimento conduzido em Cachoeirinha, RS, os autores verificaram que o volume total de água consumido durante o ciclo da cultura, no sistema convencional foi o que apresentou maior consumo $\left(7415 \mathrm{~m}^{3}\right.$ ha $^{-1}$ e vazão de $\left.0,96 \ell \mathrm{s}^{-1} \mathrm{ha}^{-1}\right)$, seguido do plantio direto $\left(6945 \mathrm{~m}^{3} \mathrm{ha}^{-1}\right.$ e vazão de $\left.0,89 \ell \mathrm{s}^{-1} \mathrm{ha}^{-1}\right)$ e plantio pré-germinado $\left(5981 \mathrm{~m}^{3} \mathrm{ha}^{-1}\right.$ e vazão de $\left.0,78 \ell \mathrm{s}^{-1} \mathrm{ha}^{-1}\right)$. Considerando-se que no sistema pré-germinado, houve um acréscimo de aproximadamente $1252 \mathrm{~m}^{3} \mathrm{ha}^{-1}$ para o preparo do solo, totalizando $7233 \mathrm{~m}^{3} \mathrm{ha}^{-1}$, o sistema plantio direto foi o que apresentou menor consumo de água.

O custo de irrigação da lavoura de arroz no Rio Grande do Sul representa $12,79 \%$ do custo total (IRGA, 1997). No entanto, o custo da irrigação poderia ser reduzido com o uso racional da água e, consequentemente, de energia. $\mathrm{O}$ desperdício de energia elétrica em estações de bombeamento de lavouras de arroz no Rio Grande do Sul foi superior a $200 \mathrm{MW}$ por safra em, aproximadamente, 6.000 estações de bombeamento em operação (ARNS, 1995).

Segundo VIANNA (1997), o consumo estimado de energia na irrigação das lavouras de arroz, no Rio Grande do Sul, é superior a 600.000 MWh por safra, o equivalente a US\$ 40 milhões. Isso representa um desperdício, em muitos casos, superior a $50 \%$ do consumo e as principais causas são o consumo de água aproximadamente $20 \%$ acima do necessário, a altura manométrica total excessivamente elevada, o rendimento de transmissão de 92 a $98 \%$ de acordo com o tipo de acoplamento da bomba ao motor e o rendimento hidráulico das bombas de 30 a $92 \%$.
Segundo MACINTYRE (1982), o rendimento total das bombas centrífugas varia de acordo com o tamanho, tipo e condições de operação, o que pode resultar em rendimentos menores de $40 \%$ e superiores a $85 \%$ para pequenas e grandes bombas, respectivamente. Um rendimento aceitável é de $60 \%$ e $75 \%$, respectivamente, para as bombas pequenas e médias. Estes valores diferenciados devem-se ao acabamento da bomba no espaço entre a carcaça e o rotor. O ideal seria que $100 \%$ do fluido recebesse a energia transferida. Entretanto, para que isso acontecesse, o custo de construção seria economicamente inviável, principalmente nas pequenas bombas.

A rotação específica é um índice do tipo de bomba para a vazão e a altura manométrica referidas ao ponto de máxima eficiência (SILVESTRE, 1979) e é calculada pela expressão: $n_{s}=n \cdot \mathrm{Q}^{1 / 2} / \mathrm{H}^{3 / 4}$ na qual: $n_{s}=$ rotação específica, em rpm; $n=$ rotação nominal da bomba, em rpm; $\mathrm{Q}=$ vazão, em $\mathrm{m}^{3} \mathrm{~s}^{-1} \mathrm{e}$ $\mathrm{H}=$ altura manométrica total, em $\mathrm{m}$.

O rendimento é muito baixo (AZEVEDO NETTO \& ALVAREZ, 1982), para bombas com rotação específica inferior a 90rpm. Os rendimentos são satisfatórios quando os valores de rotações estiverem dentro da respectiva faixa para cada tipo de bomba.

Segundo ARNS (1995), poder-se-ia reduzir em $24 \%$ o consumo de energia em algumas estações de bombeamento da Fronteira Oeste do Rio Grande do Sul, se nessas fossem redimensionadas as perdas de carga. $\mathrm{O}$ autor afirma que, mantendo as perdas de carga e substituindo os equipamentos por outros com rendimentos mínimos de $80 \%$, é possível economizar até $44 \%$ de energia. Além disso, com rendimentos de $80 \%$ e redimensionando as perdas de carga, pode ocorrer uma redução de $56 \%$ da energia consumida. Este trabalho teve como objetivo avaliar o consumo de energia e a eficiência das estações de bombeamento no sistema de irrigação por inundação contínua em lavouras de arroz da localidade de Arroio Grande, município de Santa Maria, RS.

\section{MATERIAL E MÉTODOS}

O estudo foi realizado de dezembro de 1997 a abril de 1998, nas propriedades de orizicultores pertencentes às bacias hidrográficas dos Arroios denominados de Arroio Grande e Arroio do Meio e Rio Vacacaí Mirim, localidade de Arroio Grande, Santa Maria, Rio Grande do Sul, região denominada de Depressão Central. Coordenadas geográficas aproximadas são: latitude entre $29^{0} 38^{\prime} 13^{\prime \prime}$ e $29^{\circ} 42^{\prime} 35^{\prime \prime}$, longitude entre $53^{\circ} 38^{\prime} 02^{\prime \prime}$ e 
$53^{0} 41$ '50" e altitude média de $95 \mathrm{~m}$. As coordenadas das estações de bombeamento foram obtidas através do uso de um receptor GPS (Sistema de Posicionamento Global) manual.

A velocidade da água nas tubulações de recalque foi determinada com um micro molinete instalado na extremidade da tubulação, com a hélice voltada para dentro da mesma, de acordo com a metodologia descrita por AZEVEDO NETTO \& ALVAREZ (1982). As leituras de rotação do molinete foram feitas em cinco pontos: uma no centro e quatro na disposição radial no interior da tubulação, com três repetições para cada estação de bombeamento. Para obtenção da velocidade da água através do uso do molinete, utilizou-se a expressão: $\mathrm{V}=\mathrm{a}+\mathrm{bn}$,

na qual: $\mathrm{V}=$ velocidade da água $\left(\mathrm{m} \mathrm{s}^{-1}\right) ; \mathrm{n}=$ número de rotações da hélice segundo ${ }^{-1}$ e, a e $b=$ constantes do aparelho para cada tipo de hélice utilizada.

A velocidade da água na tubulação de sucção foi obtida através da expressão:

$\mathrm{Vs}=4 . \mathrm{Q} / \pi . \mathrm{Ds}^{2}$

na qual: Vs = velocidade da água na tubulação de sucção, em m s${ }^{-1} ; \mathrm{Q}=$ vazão, $\mathrm{m}^{3} \mathrm{~s}^{-1}$ e Ds = diâmetro da tubulação de sucção, em m.

O rendimento da bomba foi determinado através da expressão:

$\eta=\gamma . \mathrm{Q} . \mathrm{H} / 75 . \mathrm{P}$

na qual: $\eta=$ rendimento da bomba, em $\% ; \gamma=$ peso específico do líquido a ser elevado (água $=1000 \mathrm{~kg}$ $\left.\mathrm{m}^{-3}\right) ; \mathrm{Q}=$ vazão, em $\mathrm{m}^{3} \mathrm{~s}^{-1} ; \mathrm{H}=$ altura manométrica total, em $\mathrm{m}$ e $\mathrm{P}=$ potência absorvida pela bomba, em CV.

O consumo de energia nos motores elétricos das estações de bombeamento foi determinado com um amperímetro que registrou a corrente elétrica dos cabos elétricos ligados ao quadro de comando que alimentavam o motor. Com os dados de corrente elétrica, obteve-se o consumo de energia elétrica através da expressão:

$\mathrm{P}_{(\mathrm{KW})}=\sqrt{3}$.I.E.Cos $\varphi / 1000$

na qual: $\mathrm{P}=$ potência fornecida, em $\mathrm{KW} ; \sqrt{3}=$ motores trifásicos com corrente alternada; I = corrente elétrica, em ampères; $\mathrm{E}=$ tensão, em Volts e $\operatorname{Cos} \varphi=$ fator de potência do motor.

Nos motores diesel, o consumo de energia (litros de óleo diesel por hora) foi quantificado colocando-se o motor em funcionamento na rotação da bomba usualmente utilizada. $\mathrm{O}$ reservatório de combustível foi completamente preenchido e, após uma hora, desligou-se o motor e mediu-se o volume de combustível utilizado para completar o reservatório.
A obtenção das potências consumida (motores diesel) e necessária (motores diesel e elétricos) foi através da vazão fornecida, altura manométrica total e rotação da bomba. Com estes parâmetros, foi possível determinar as potências (consumida e necessária), através das curvas características das bombas centrífugas fornecidas pelos fabricantes BARROS (1980), KERBER (1987) e MERNAK (1987).

A necessidade de água para irrigação foi obtida com os dados de evaporação do tanque classe "A" da Estação Meteorológica do Departamento de Fitotecnia da Universidade Federal de Santa Maria, em Santa Maria, RS (normais 1979 a 1998). Foi considerada a evapotranspiração acrescida de $30 \%$ de perdas como necessidade de irrigação.

A evapotranspiração foi estimada segundo BEISDORF \& MOTA (1976), que utilizaram para o Rio Grande do Sul, registros de evaporação do tanque classe "A" por ser um meio simples e com boa correlação $(\mathrm{R}=0,93)$ com a evapotranspiração medida na cultura do arroz irrigado, obtida através da expressão:

$\mathrm{Y}=1,84+0,91 \mathrm{X}$

na qual: $\mathrm{Y}=$ evapotranspiração potencial do arroz irrigado $(\mathrm{mm})$ e $\mathrm{X}=$ evaporação do tanque classe "A"(mm).

Segundo IRGA (1997), no cálculo do custo de produção é atribuído que as motobombas devem operar num regime de 16 horas diárias, com exceção dos primeiros 10 dias de irrigação, que serão absorvidas as 24 horas diárias em funcionamento, para assegurar a inundação adequada das lavouras. Este regime de trabalho foi considerado neste estudo para o cálculo da vazão necessária que é de $1,67 \ell \mathrm{s}^{-1} \mathrm{ha}^{-1}$.

Adotou-se 90 dias como período de irrigação, uma vez que $73 \%$ dos cultivares de arroz utilizados na região na safra 1997/98, eram de ciclo semi-precoce (110 a 120 dias).

\section{RESULTADOS E DISCUSSÃO}

A velocidade da água nas tubulações de sucção (100\% das estações) e de recalque $(76 \%$ das estações) foram maiores que o recomendado por CARVALHO (1984), que preconiza valores médios de 1 e $2 \mathrm{~m} \mathrm{~s}^{-1}$ nas tubulações de sucção e de recalque, respectivamente (Tabela 1). Estes valores devem-se ao pequeno diâmetro das tubulações utilizadas, que pode ser atribuído a uma tentativa de redução de custos na aquisição ou ao mau dimensionamento dos equipamentos. Deve-se ressaltar que a alta 
Tabela 1 - Características das estações de bombeamento avaliadas, acionadas por motores e tratores a óleo diesel e motores elétricos. Santa Maria - RS, 1997/98.

\begin{tabular}{|c|c|c|c|c|c|}
\hline \multirow{2}{*}{$\begin{array}{l}\mathrm{N}^{0} \text { da estação } \\
\text { de bombea- } \\
\text { mento }\end{array}$} & \multirow{2}{*}{$\begin{array}{c}\text { Altura } \\
\text { manométri- } \\
\mathrm{ca}(\mathrm{m})\end{array}$} & \multirow{2}{*}{$\begin{array}{l}\text { Rotação } \\
\text { específica } \\
\text { (rpm) }\end{array}$} & \multirow{2}{*}{$\begin{array}{c}\text { Rendimento } \\
\text { da bomba } \\
(\%)\end{array}$} & \multicolumn{2}{|c|}{$\begin{array}{l}\text { Velocidade da água } \\
\left(\mathrm{m} \mathrm{s}^{-1}\right)\end{array}$} \\
\hline & & & & Sucção & Recalque \\
\hline 1 & 6,64 & 48 & 51 & 2,56 & 2,56 \\
\hline 2 & 6,75 & 57 & 77 & 2,49 & 1,90 \\
\hline 3 & 7,54 & 59 & 36 & 1,90 & 1,14 \\
\hline 4 & 14,64 & 59 & 82 & 5,49 & 3,08 \\
\hline 5 & 6,26 & 63 & 74 & 3,38 & 3,38 \\
\hline 6 & 10,85 & 40 & 85 & 2,80 & 2,80 \\
\hline 7 & 4,81 & 56 & 47 & 2,60 & 3,36 \\
\hline 8 & 6,68 & 71 & 79 & 3,39 & 2,85 \\
\hline 9 & 7,03 & 72 & 66 & 3,29 & 1,85 \\
\hline 10 & 7,46 & 54 & 61 & 2,84 & 2,84 \\
\hline 11 & 7,94 & 60 & 68 & 3,40 & 2,55 \\
\hline 12 & 7,46 & 64 & 63 & 4,61 & 1,80 \\
\hline 13 & 8,43 & 51 & 76 & 2,30 & 2,30 \\
\hline 14 & 5,98 & 45 & 61 & 3,13 & 2,40 \\
\hline 15 & 7,51 & 61 & 82 & 3,34 & 2,15 \\
\hline 16 & 5,43 & 71 & 39 & 2,08 & 1,71 \\
\hline 17 & 7,53 & 58 & 54 & 2,67 & 2,88 \\
\hline 18 & 8,39 & 60 & 78 & 3,50 & 2,80 \\
\hline 19 & 6,22 & 69 & 48 & 2,90 & 2,90 \\
\hline 20 & 8,88 & 57 & 74 & 3,50 & 3,45 \\
\hline 21 & 8,60 & 51 & 70 & 3,12 & 3,43 \\
\hline Média & 7,67 & 58 & 65 & 3,11 & 2,58 \\
\hline
\end{tabular}

rotações específicas das bombas foram elevadas, devido, principalmente, às altas rotações necessárias para compensar o baixo desempenho dos equipamentos. No entanto, as altas rotações aumentam o desgaste e, consequentemente, reduzem a vida útil do conjunto motobomba.

Das 21 bombas avaliadas, dez $(47,6 \%)$ apresentaram rendimento abaixo do limite inferior e apenas uma $(4,8 \%)$ acima do limite superior (Figura 1). Este baixo rendimento pode ser atribuído à alta potência absorvida em relação à vazão fornecida, devido ao pequeno diâmetro da tubulação e ao desgaste e manutenção inadequada dos equipamentos do conjunto motobomba.

Em $81 \%$ das bombas avaliadas, o rendimento ficou comprometido, portanto, fora dos limites das curvas (Figura 2). Isso demonstra o alto grau de precariedade dos equipamentos em operação, demandando potências elevadas para compensar as perdas.

Analisando-se a tabela 2, observase uma grande desproporcionalidade entre as fontes de potência e a relação entre potência nominal e área irrigada, a qual se apresentou

velocidade da água nas tubulações resulta no incremento da altura manométrica, que é diretamente proporcional à potência absorvida pela bomba. No entanto, se fossem redimensionadas as tubulações para proporcionar velocidades da água nas tubulações de sucção e recalque, respectivamente, 1 e $2 \mathrm{~m} \mathrm{~s}^{-1}$ e vazão de $1,67 \ell \mathrm{s}^{-1} \mathrm{ha}^{-1}$, poder-se-ia economizar $29 \%$ de energia elétrica. Mas, se além disso, as atuais motobombas fossem substituídas por outras com rendimentos mínimos de $75 \%$, reduzir-se-ia em $41 \%$ o consumo de energia elétrica.

$\mathrm{O}$ rendimento das bombas fo insatisfatório, pois $67 \%$ das mesmas, apresentaram índices abaixo do aceitável para bombas de porte médio que, de acordo com MACINTYRE (1982), deve ser de 75\%.

A altura manométrica total média foi de aproximadamente $8 \mathrm{~m}$ (Tabela 1 ) e pode ser considerada razoavelmente baixa em relação a encontrada por ARNS (1995) na Fronteira Oeste do Rio Grande do Sul (18m). No entanto, esta poderia ser ainda menor se as atuais tubulações fossem substituídas por outras de maior diâmetro. Verificou-se ainda que as elevada e extremamente elevada para, respectivamente, motores elétricos e tratores. Potências de $0,5 \mathrm{CV}$ ha $^{-1}$ para motores elétricos e $0,75 \mathrm{CV} \mathrm{ha}^{-1}$ para motores diesel seriam suficientes para suprir a demanda para as estações de bombeamento (IRGA, 1997). Estes resultados demonstram que os conjuntos motobombas abastecidos por energia elétrica, apesar de precários, são dimensionados com certos critérios técnicos exigidos pela concessionária fornecedora de energia. As estações de bombeamento acionadas por tratores, também apresentaram uma alta relação $\mathrm{CV}$ ha $^{-1}$ que pode ser atribuída a muitas dessas instalações serem

Tabela 2 - Tratores diesel, motores estacionários elétricos e diesel, potência total, área irrigada pelas diferentes fontes de potência e potência instalada por hectare. Santa Maria - RS, 1997/98.

\begin{tabular}{lccclc}
\hline Fonte de Potência & Total & $(\%)$ & $\begin{array}{l}\text { Potência } \\
\text { nominal } \\
\text { total (CV) }\end{array}$ & $\begin{array}{l}\text { Área de } \\
\text { lavoura } \\
\text { irrigada (ha) }\end{array}$ & CV ha $^{-1}$ \\
\hline Motores estac. elétricos & 31 & 41 & 431,00 & 461 & 0,93 \\
Motores estac. diesel & 12 & 16 & 213,50 & 101 & 2,11 \\
Tratores diesel & 33 & 43 & 2345,00 & 372 & 6,30
\end{tabular}




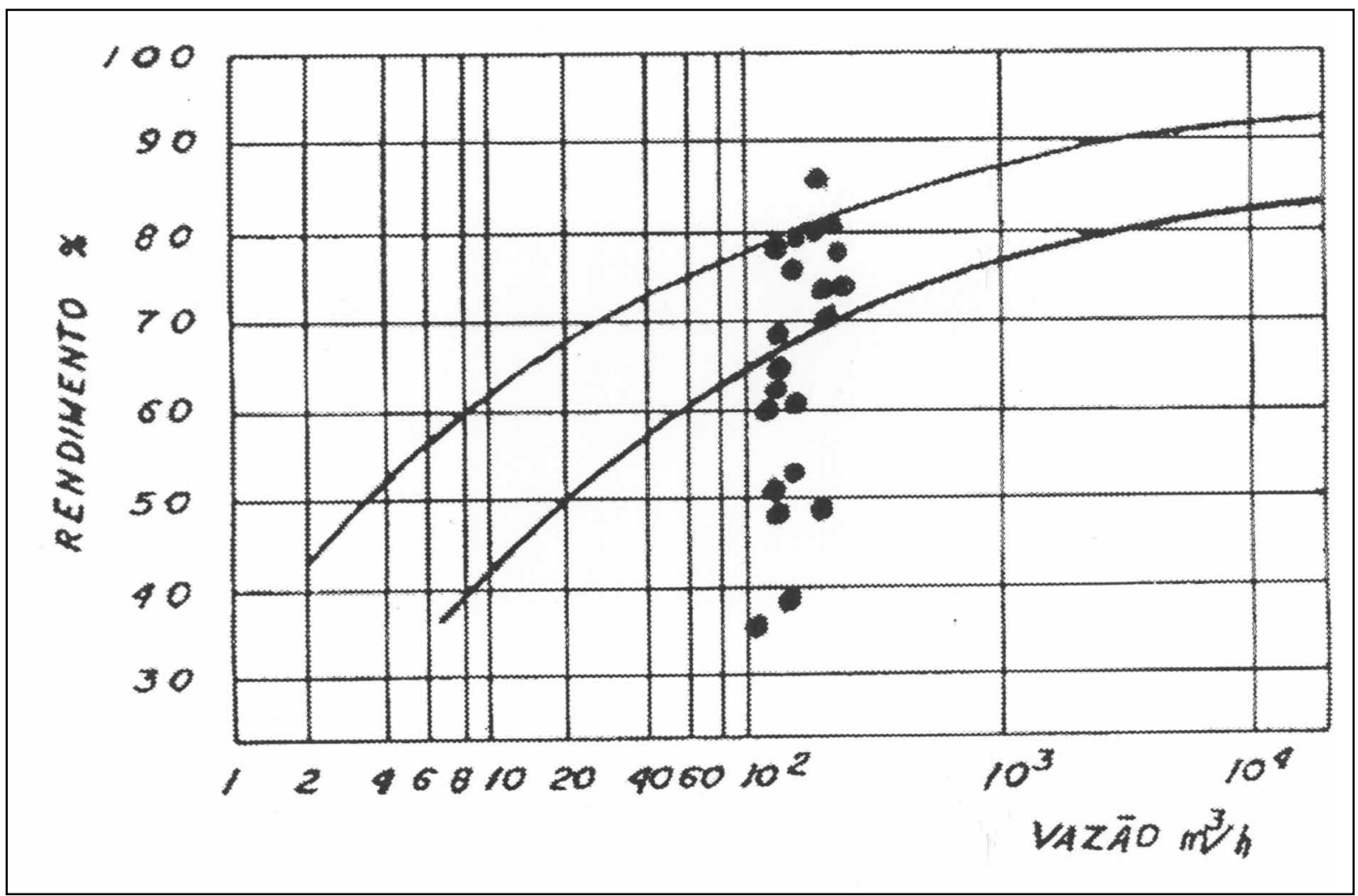

Figura 1 - Rendimento de bombas hidráulicas em função da vazão.

improvisadas, distantes da rede elétrica as quais teriam um alto custo inicial para serem substituídas por motores elétricos. A extremamente alta relação $\mathrm{CV} \mathrm{ha}{ }^{-1}$, encontrada na utilização de tratores (Tabela 2), demonstra a precariedade na administração do consumo de energia, representando aumento no custo de produção.

Com base na vazão de $1,67 \ell \mathrm{s}^{-1} \mathrm{ha}^{-1}$, obtida com a expressão 6 acrescida de $30 \%$ de perdas (condução e distribuição da água, percolação e infiltração lateral), num regime de trabalho de 16 horas diárias, foi elaborada a figura 3 , na qual consta os valores de potência instalada, necessária e consumida. Em função da área irrigada, há grande diferença entre as potências consumida e necessária e, principalmente, entre as potências necessária e instalada que apresentam valores de 200 a $4250 \%$. Deve-se considerar que, na maioria das estações do estudo, o regime de trabalho é, em média, de aproximadamente 10 horas diárias. Mas, mesmo assim, por serem utilizadas grandes vazões em lavouras pequenas, esse volume de água é superior ao necessário e parte dessa água acaba escorrendo superficialmente para os drenos. Isso proporciona muitas vezes, juntamente com a altura manométrica elevada e o baixo rendimento das bombas, desperdício de energia superior a 50\%. Estes valores concordam com VIANNA (1997) para quem, o consumo excessivo de água, altura manométrica elevada e o baixo rendimento das bombas são as principais causas do desperdício de energia. Nota-se ainda que a potência instalada foi superior a consumida, o que revela um superdimensionamento dos equipamentos, que resulta em desperdício de energia ocasionado por um bombeamento desnecessário.

\section{CONCLUSÕES}

Há desperdício de energia utilizada na irrigação de lavouras de arroz na localidade de Arroio Grande, Santa Maria, RS. Os conjuntos motobombas estão superdimensionados e utilizam tubulações de diâmetro inferior ao mínimo recomendado. A maioria das bombas avaliadas apresentam índices de rendimentos inferiores ao mínimo desejável e as potências nominais instaladas estão acima das necessárias. As estações de bombeamento podem economizar $29 \%$ de energia elétrica com o redimensionamento das perdas de carga. A substituição das atuais motobombas por outras com rendimentos mínimos de $75 \%$ somada 


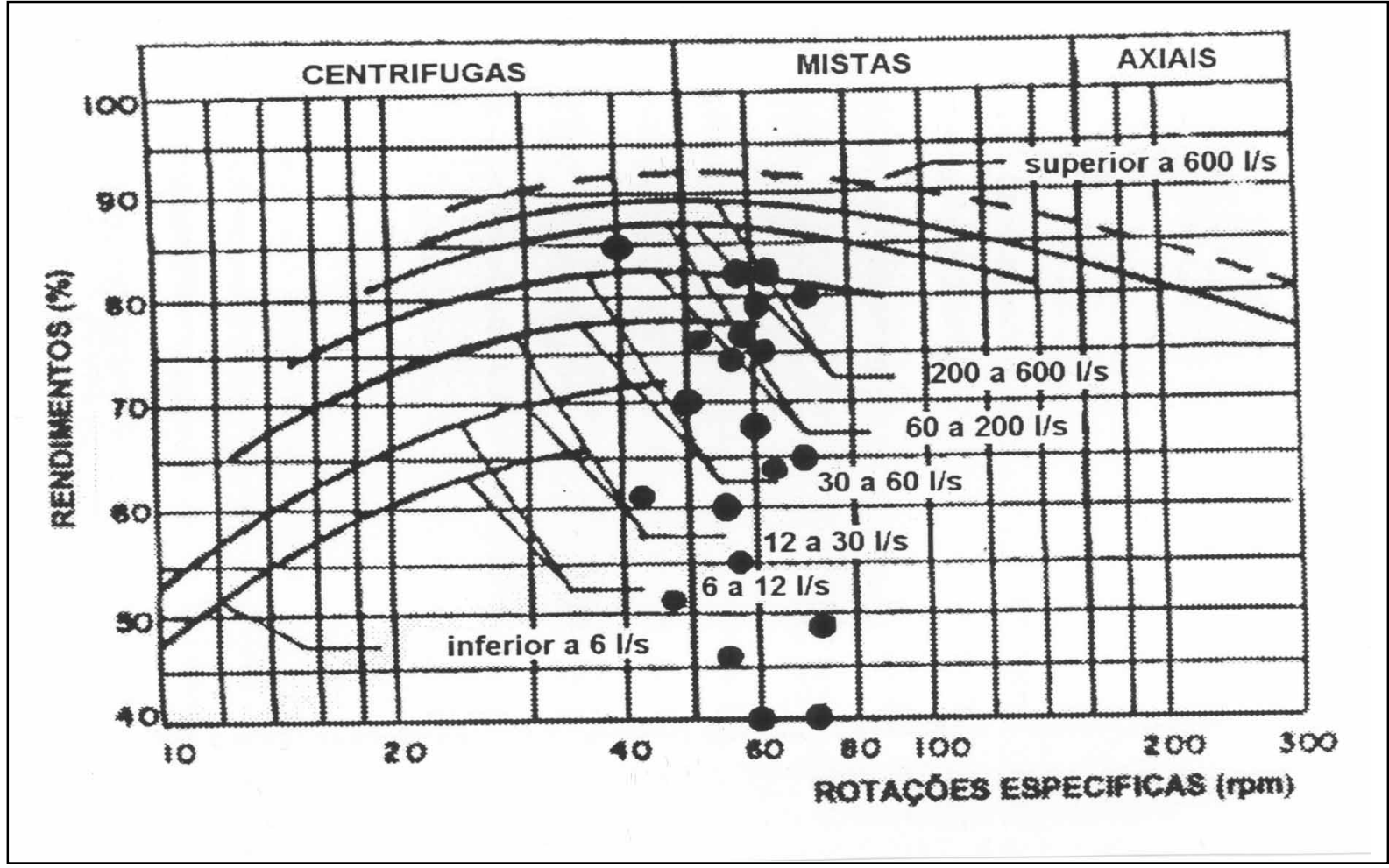

Figura 2 - Rendimento de bombas hidráulicas em função das rotações específicas para diferentes vazões.

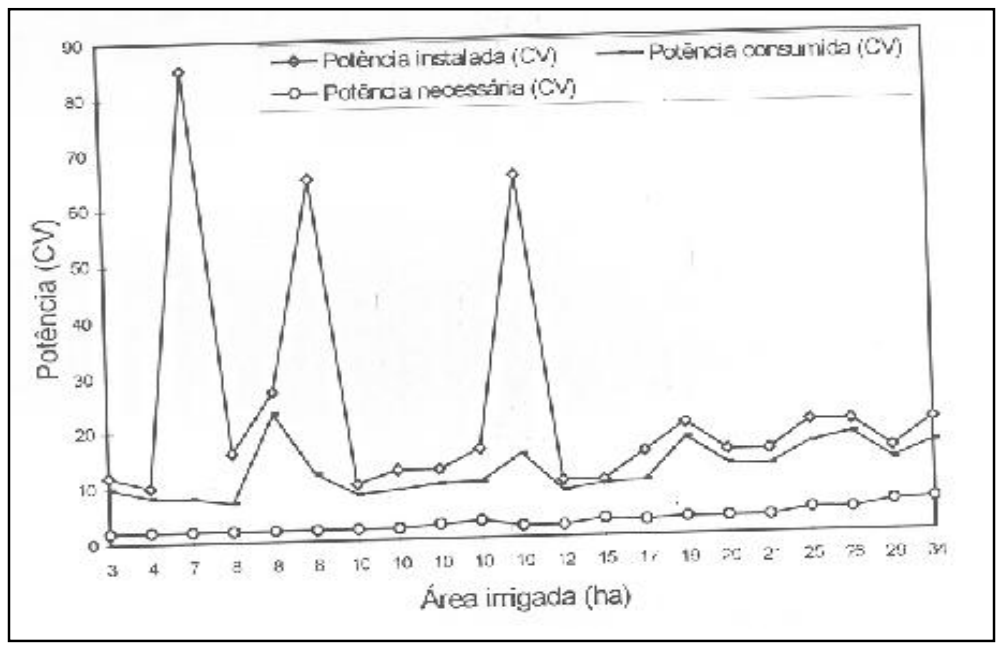

Figura 3 - Valores de potência instalada, consumida e necessária calculadas para a vazão de $1,67 \ell \mathrm{s}^{-1} \mathrm{ha}^{-1}$, em função da área irrigada. Santa Maria - RS $1997 / 98$. elétrica em bombeamentos de arrozais na Fronteira-Oeste do Rio Grande do Sul. Lavoura Arrozeira, Porto Alegre, v.48, n.418, p.14-17, jan./fev. 1995.

AZEVEDO NETTO, J.M. de, ALVAREZ, G. A. Manual de hidráulica. 7.ed. rev. e compl. São Paulo : Edgard Blücher, 1982. 2v. ilust. 2v. ilust. 723 p.

BARROS. Manual técnico de bombas. 1980. BEISDORF, M.T. MOTA, F.S. Evapotranspiração do arroz irrigado em Pelotas, Rio Grande do Sul. Ciência e Cultura, São Paulo, v.28, n.11, p.1329-1334, 1976.

BELTRAME, L.F.S., GONDIM, L.A.O Estudo hidrológico do consumo de água em lavoura de arroz. Lavoura Arrozeira, Porto Alegre, v.35, n.333, p.22-28, jan./fev, 1982. com o redimensionamento das atuais perdas de carga, possibilitará economia de até $41 \%$ de energia elétrica.
CARVALHO, D.F. Instalações elevatórias: Bombas. 3.ed. Belo Horizonte : Departamento de Engenharia Civil, IPUC. FUMARC, 1984. 355p.

\section{REFERÊNCIAS BIBLIOGRÁFICAS}

ARNS, R. Racionalização do uso de energia

Ciência Rural, v. 32, n. 2, 2002. 
CONAB. Estimativas de safras. Indicadores da Agropecuária. Brasília, v.9, n.2, p.8, fev. 2000.

EMBRAPA - Centro de Pesquisa Agropecuária de Clima Temperado (Pelotas, RS). Arroz irrigado: recomendações técnicas da pesquisa para o sul do Brasil. Pelotas, 1999. 124p.

INSTITUTO RIOGRANDENSE DO ARROZ (IRGA). Custo de produção do arroz. Porto Alegre, v.12, m.1, p.1-47, out. 1997. Produção brasileira de arroz. Informativo. v.8, n.1, jan./fev. 2000 .

KERBER. Manual técnico de bombas. S.1, 1987.

MACINTYRE, A.J. Bombas e instalações de bombeamento. Rio de Janeiro : Guanabara Dois, 1982. 667p.

MARCOLIN, E., CORRÊA, N. I., LOPES, M. S., et al. Determinação do consumo de água em três sistemas de cultivo de arroz irrigado. In: CONGRESSO BRASILEIRO DE ARROZ IRRIGADO, 1; REUNIÃO DA CULTURA DO ARROZ IRRIGADO, 23, 1999. Pelotas, RS. Anais... Pelotas : Embrapa Clima Temperado, 1999. p.263-265.
MERNAK. Bombas centrífugas. S.1., 1987.

MOTA, F.S., ALVES, E.G.P., BECKER, C.T. Informação climática para planejamento da necessidade de água para irrigação do arroz no Rio Grande do Sul. Lavoura Arrozeira, Porto Alegre, v.43, n.392, p.3-6, set./out, 1990

OLITA, A.F.L. Os métodos de irrigação. São Paulo : Nobel, 1985. 267p.

QUINTELA, A.C. Hidráulica. Lisboa : Fundação Calouste Gulbenkian, 1981. Cap.15: Turbo máquinas hidráulicas: p.393-487.

SILVESTRE, P. Hidráulica geral. Rio de Janeiro : Livros Técnicos e Científicos, 1979. 316p.

VIANNA, M.L. de S. O desperdício de energia na irrigação do arroz. Lavoura Arrozeira, Porto Alegre, v.50, n.432, p.911, jul./ago. 1997.

WEG. Motores assíncronos de indução trifásicos. Motores trifásicos. S.1, 1980.

Ciência Rural, v. 32, n. 2, 2002. 